\title{
Correction to: The role of fat on cardiomyopathy outcome in mouse models of chronic Trypanosoma cruzi infection
}

\author{
Paul Zaki ${ }^{1}$ - Elisa L. B. C. Domingues ${ }^{2}$ - Farhad M. Amjad ${ }^{1} \cdot$ Maiara B. Narde $^{2} \cdot$ Karolina R. Gonçalves $^{3} \cdot$ \\ Mirelle L. Viana ${ }^{2}$ - Heberth de Paula ${ }^{2}$. Wanderson G. de Lima ${ }^{4}$ • Huan Huang ${ }^{1}$ - Maria T. Bahia ${ }^{3,4}$. \\ Philipp E. Scherer ${ }^{5}$ Fabiane M. dos Santos ${ }^{2}$ - Louis M. Weiss ${ }^{1,6} \cdot$ Herbert B. Tanowitz ${ }^{1,6}$
}

Published online: 20 April 2020

(C) Springer-Verlag GmbH Germany, part of Springer Nature 2020

\section{Correction to: Parasitol Res}

https://doi.org/10.1007/s00436-020-06645-z

The authors regret that Philipp E Scherer's name was spelt incorrectly in the author list. The name of the author is now corrected above.

The original article has been corrected.

Publisher's note Springer Nature remains neutral with regard to jurisdictional claims in published maps and institutional affiliations.

The online version of the original article can be found at https://doi.org/ $10.1007 / \mathrm{s} 00436-020-06645-\mathrm{Z}$

Louis M. Weiss

louis.weiss@einsteinmed.org

Fabiane M. dos Santos

fab.matoss@hotmail.com

1 Department of Pathology, Albert Einstein College of Medicine, 1300 Morris Park Avenue, Bronx, NY 10461, USA

2 Department of Pharmacy and Nutrition, Federal University of Espírito Santo, Guararema, Alegre, ES 29500-000, Brazil

3 School of Medicine, Federal University of Ouro Preto, Morro do Cruzeiro, Ouro Preto, MG 35400-000, Brazil

4 Department of Biological Sciences, Federal University of Ouro Preto, Morro do Cruzeiro, Ouro Preto, MG 35400-000, Brazil

5 The Touchstone Diabetes Center, UT Southwestern Medical Center, 5323 Harry Blvd, Dallas, TX 75390, USA

6 Department of Medicine, Albert Einstein College of Medicine, 1300 Morris Park Avenue, Bronx, NY 10461, USA 